\title{
Rituximab Treatment for Nephrotic Syndrome in Children
}

\author{
Kazumoto Iijima $\cdot$ Mayumi Sako $\cdot$ Kandai Nozu
}

Published online: 6 December 2014

(C) The Author(s) 2014

\begin{abstract}
In the past 10 years, many reports have suggested that rituximab, a chimeric anti-CD20 monoclonal antibody, is effective for children with complicated, frequently relapsing or steroid-dependent nephrotic syndrome (FRNS/SDNS). However, those reports were case reports, case series, retrospective surveys, and single-arm or shortterm trials. Therefore, well-designed controlled trials are required to establish the value of rituximab in this condition. To evaluate the efficacy and safety of rituximab in childhood-onset, complicated FRNS/SDNS, a multicenter, double-blind, randomized, placebo-controlled trial was carried out by the Research Group of Childhood-onset Refractory Nephrotic Syndrome (RCRNS) in Japan (RCRNS01). RCRNS01 showed that rituximab is safe and effective for the treatment of childhood-onset, complicated FRNS/SDNS. In 2014, the use of rituximab for patients with complicated FRNS/SDNS was approved, first in the world, by the Ministry of Health, Labour and Welfare, Japan.
\end{abstract}

This article is part of the Topical Collection on Renal.

K. Iijima $(\bowtie) \cdot$ K. Nozu

Department of Pediatrics, Kobe University Graduate School of Medicine, 7-5-2 Kusunoki-cho, Chuo-ku, Kobe 650-0017, Japan e-mail: iijima@med.kobe-u.ac.jp

K. Nozu

e-mail: nozu@med.kobe-u.ac.jp

M. Sako

Division for Clinical Trials, Department of Development Strategy, Center for Social and Clinical Research, National Research Institute for Child Health and Development, National Center for Child Health and Development, 2-10-1 Okura, Setagaya-ku, Tokyo 157-8535, Japan

e-mail: sako-m@ncchd.go.jp
Keywords Rituximab - Nephrotic syndrome $\cdot$ Frequently relapsing · Steroid-dependent · Multicenter, double-blind, randomized, placebo-controlled trial

\section{Introduction}

Children afflicted with nephrotic syndrome lose proteins to urine, resulting in hypoproteinemia and generalized edema. Idiopathic nephrotic syndrome occurs in two or more children out of 100,000 [1] and is the most common chronic glomerular disease in children. Many patients have minimal change nephrotic syndrome, and most respond well to steroid therapy, but up to half of them develop frequently relapsing nephrotic syndrome or steroid-dependent nephrotic syndrome (FRNS/SDNS) [2]. A total of $10-20 \%$ of idiopathic nephrotic syndrome patients show steroid resistance (steroid-resistant nephrotic syndrome: SRNS), defined as persisting proteinuria after a 4-week course of oral steroids [2]. Standard treatments for FRNS/ SDNS are immunosuppressive agents, such as cyclophosphamide, chlorambucil, cyclosporine (CyA), and levamisole, and CyA is often used for treatment of SRNS [3-5]. Most affected children are helped by these drugs; however, some still show complicated clinical courses. A total of 10-20\% of children with FRNS/SDNS on CyA have frequent relapses [6, 7], and approximately $30 \%$ of childhood SRNS patients have steroid-sensitive frequent relapses after achievement of complete remission [8]. In addition, CyA can cause side effects, especially chronic nephrotoxicity $[9,10]$, suggesting that CyA treatment should be discontinued after its long-term use. However, discontinuing CyA almost always results in frequent relapses or steroid dependence, requiring long-term steroid therapies, which also pose a long-term risk to children. Collectively, 
at least $10-20 \%$ of children with idiopathic nephrotic syndrome still show frequent relapses or steroid dependence under or after immunosuppressive therapies. We have defined these conditions as "complicated FRNS/ SDNS". Additionally, approximately $2-3 \%$ of children with idiopathic nephrotic syndrome show resistance for steroids and any immunosuppressive agents, which is defined as "refractory SRNS", posing a high risk of endstage renal failure (Table 1). Therefore, development of new treatments for complicated FRNS/SDNS and for refractory SRNS is urgently needed.

\section{Rituximab Treatment for Nephrotic Syndrome}

Rituximab is a chimeric anti-CD20 monoclonal antibody, which inhibits CD20-mediated B-cell proliferation and differentiation, resulting in depletion of peripheral blood $\mathrm{B}$ lymphocytes. This drug was developed for the treatment of B-cell non-Hodgkin's lymphoma and is now indicated for the treatment of patients with autoimmune diseases,

Table 1 Definitions of terms in nephrotic syndrome

\begin{tabular}{|c|c|}
\hline $\begin{array}{l}\text { Frequent relapsing } \\
\text { nephrotic syndrome } \\
\text { (FRNS) }\end{array}$ & $\begin{array}{l}\text { Two or more relapses within } 6 \text { months } \\
\text { after initial remission or } 4 \text { or more } \\
\text { relapses within any 12-month period }\end{array}$ \\
\hline $\begin{array}{l}\text { Steroid-dependent } \\
\text { nephrotic syndrome } \\
\text { (SDNS) }\end{array}$ & $\begin{array}{l}\text { Two consecutive relapses during the } \\
\text { reduction of steroid therapy or within } \\
2 \text { weeks of discontinuation of steroid } \\
\text { therapy }\end{array}$ \\
\hline $\begin{array}{l}\text { Steroid-resistant nephrotic } \\
\text { syndrome (SRNS) }\end{array}$ & $\begin{array}{l}\text { When the daily administration of } \\
\text { prednisolone at } 60 \mathrm{mg} / \mathrm{m}^{2} / \text { day does } \\
\text { not lead to remission within } 4 \text { weeks }\end{array}$ \\
\hline \multirow[t]{3}{*}{ Complicated FRNS/SDNS } & $\begin{array}{l}\text { (1) Diagnosed with frequent relapse } \\
\text { (FRNS) or steroid dependence } \\
\text { (SDNS) after completion of } \\
\text { immunosuppressive drug therapy } \\
\text { (such as cyclosporine, } \\
\text { cyclophosphamide, mizoribine, or } \\
\text { mycophenolate mofetil) }\end{array}$ \\
\hline & $\begin{array}{l}\text { (2) Diagnosed with frequent relapse } \\
\text { (FRNS) or steroid dependence } \\
\text { (SDNS) during immunosuppressive } \\
\text { drug therapy (such as cyclosporine, } \\
\text { cyclophosphamide, mizoribine, or } \\
\text { mycophenolate mofetil) }\end{array}$ \\
\hline & $\begin{array}{l}\text { (3) With a history of steroid resistance } \\
\text { and diagnosed with frequent relapse } \\
\text { or steroid dependence during or after } \\
\text { the completion of immunosuppressive } \\
\text { drug therapy (such as cyclosporine or } \\
\text { combination of cyclosporine and } \\
\text { methylprednisolone) }\end{array}$ \\
\hline Refractory SRNS & $\begin{array}{l}\text { When the combination of steroids and } \\
\text { immunosuppressive agents including } \\
\text { calcineurin inhibitors does not lead to } \\
\text { remission }\end{array}$ \\
\hline
\end{tabular}

including rheumatoid arthritis, Wegener's granulomatosis, and microscopic polyangiitis $[11,12]$.

In the past 10 years, there have been anecdotal reports of rituximab being effective for nephrotic syndrome. In 2004, a patient suffering from SDNS complicated with idiopathic thrombocytopenic purpura underwent rituximab treatment, resulting in long-term remission of nephrotic syndrome and idiopathic thrombocytopenic purpura [13]. In 2005, Nozu et al. reported that rituximab treatment induced long-term remission in recurrent nephrotic syndrome and posttransplant lymphoproliferative disorder after renal transplantation [14]. The findings from their report were confirmed by Pescovits et al. in 2006 [15]. However, other reports have shown that none of the patients treated with rituximab achieved remission in recurrent nephrotic syndrome after renal transplantation [16]. Bagga et al. reported three complete and two partial remissions in five patients with refractory SRNS receiving rituximab [17]. Kamei et al. treated 10 children with refractory SRNS with additional rituximab and methylprednisolone pulse therapy. Seven patients achieved complete remission and preserved normal renal function without proteinuria [18]. Although other case reports and case series, as well as the above-mentioned reports, have suggested that rituximab treatment is effective in some patients with refractory SRNS [19-24], there is no evidence that rituximab is effective in patients with refractory SRNS. Indeed, Magnasco et al. reported the results of an open-label, randomized trial including 31 children with refractory SRNS who received calcineurin inhibitors and prednisolone, and 16 of them received an additional two rituximab infusions. However, proteinuria remained unchanged in rituximab-treated patients and none of them had partial or complete remission [25].

Several case reports and case series, as well as survey studies, have suggested that rituximab is effective for patients with complicated (difficult to treat) FRNS/SDNS, allowing discontinuation or reduction steroids and/or immunosuppressants [22, 24, 26-30]. Recent relatively large case series have also shown promising results. Ravani et al. treated 46 children with idiopathic nephrotic syndrome maintained in remission with steroids and calcineurin inhibitors (i.e., complicated FRNS/SDNS) with one to five rituximab courses. They found that the 6-month probability of remission was $48 \%$ after the first remission [31•]. Ruggenenti et al. reported the effects of rituximab therapy followed by immunosuppression withdrawal on disease recurrence in 30 patients (including 10 children) with complicated FRNS/SDNS. In their report, participants received one or two doses of rituximab, and all of them were in remission at 1 year [32•]. Ravani et al. conducted an open-label, randomized, controlled trial to examine the short-term effects of rituximab in children with steroid- and 
calcineurin-dependent nephrotic syndrome (i.e., complicated FRNS/SDNS). They concluded that rituximab and lower doses of prednisone and calcineurin inhibitors are non-inferior to standard therapy in maintaining short-term remission [33॰]. Taken together, these findings suggest that rituximab is effective for children with complicated FRNS/ SDNS. However, these studies were case reports, case series, retrospective surveys, and single-arm or short-term trials. Therefore, well-designed controlled trials are required to establish the value of rituximab in this condition.

\section{A Multicenter, Double-Blind, Randomized, Placebo- Controlled Trial of Rituximab Therapy for Childhood- Onset Complicated FRNS/SDNS}

To evaluate the efficacy and safety of rituximab in childhoodonset complicated FRNS/SDNS, a multicenter, double-blind, randomized, placebo-controlled trial was carried out by the Research Group of Childhood-onset Refractory Nephrotic Syndrome (RCRNS) in Japan (RCRNS01) (Clinical Trials Registry ID: UMIN000001405). At the same time, an openlabel, multicenter, pharmacokinetic trial (RCRNS-02) (Clinical Trials Registry ID: UMIN000001406) was also carried out. These two trials were investigator-initiated clinical trials, which sought to gain approval from the Ministry of Health, Labour and Welfare, Japan to make rituximab available for patients with childhood-onset complicated FRNS/SDNS. These trials were supported by a Health and Labor Sciences Research Grant for the Large Scale Clinical Trial Network Project (CCT-B-2001). The study design of RCRNS01 is shown in Fig. 1. The protocol for RCRNS01 is available at http://www.med.kobe-u.ac.jp/pediat/pdf/rcrn01. pdf. When patients developed relapse of nephrotic syndrome, they underwent a screening examination and were registered once their eligibility, including steroid sensitivity, was verified. The rituximab group received intravenous rituximab of $375 \mathrm{mg} / \mathrm{m}^{2}$ body surface area (maximum $500 \mathrm{mg}$ ) once weekly for 4 weeks, and the placebo group received placebo at the same frequency. Prednisolone treatment was gradually discontinued after obtaining remission, and patients were treated with prednisolone when they developed relapses during the study period. Tapering of the CyA dose was started on day 85 , and the drug was discontinued by day 169 . Other immunosuppressive agents were discontinued by day 85 . All of the patients were observed for 1 year, unless the patients dropped out of the study. Patients were considered to have treatment failure if (1) relapse occurred by Day 85, (2) FRNS or SDNS was diagnosed between Day 86 and Day 365, or (3) steroid resistance was diagnosed during the observation period. The primary endpoint was the relapse-free period. The secondary endpoints were time-to-treatment failure, relapse rate, time to FRNS/SDNS, and steroid dose after randomization. Safety endpoints, including frequency and severity of adverse events, were also evaluated. A gold standard, double-blind, placebo-controlled trial was adopted because the use of rituximab in treatment of nephrotic syndrome was not yet approved in any country. In the trial, treatment failures were defined, and in the event that patients had treatment failure, the allocation code was urgently disclosed. If patients were allocated to the placebo group, they were able to enter a separately conducted rituximab pharmacokinetic trial (RCRNS02) after discontinuation or completion of RCRNS01.

Sixty-three patients were screened, and 52 were randomized. Twenty-seven patients were allocated to the rituximab group and 25 to the placebo group. Twenty-four patients in each group (total 48) received the intervention
Fig. 1 Study design. NS nephrotic syndrome, $M M F$ mycophenolate mofetil, $M Z B$ mizoribine, $C y A$ cyclosporine

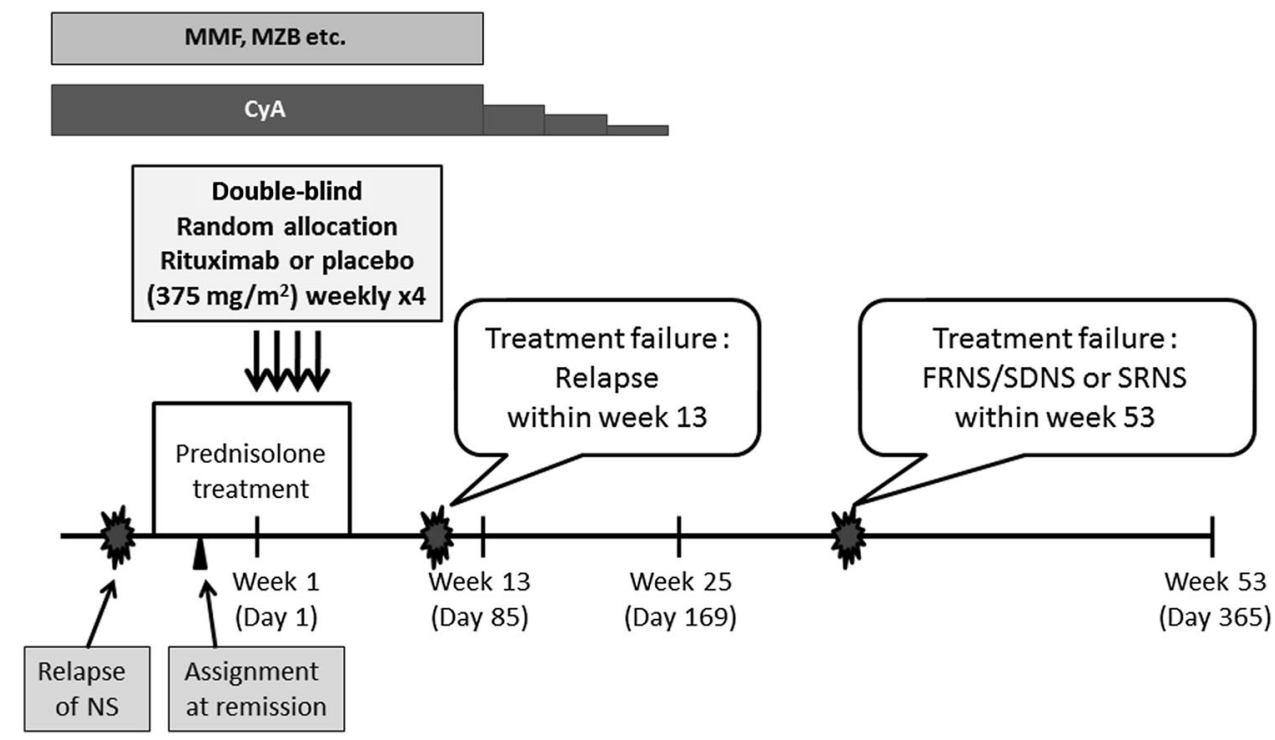


and were included in the analysis on an intention-to-treat basis. Four patients from the rituximab group and 20 from the placebo group had discontinued the intervention, mostly because of treatment failure. However, no patients dropped out of the study before the first relapse (the primary endpoint). All of the patients with treatment failure in the placebo group were enrolled into RCRNSO2 after discontinuation $(N=18)$ or completion $(N=2)$ of RCRNS01. Baseline characteristics were similar between the two groups. All of the patients were treated with steroids and/or immunosuppressants at relapse immediately before assignment. Over $70 \%$ of patients reported side effects from steroid treatment.

By the end of the observation period, relapses were reported in 17 patients in the rituximab group and 23 in the placebo group. The $50 \%$ relapse-free period was 267 days [95\% confidence interval (CI) 223-374 days] in the rituximab group and 101 days (95\% CI 70-155 days) in the placebo group. This relapse-free period was significantly longer in the rituximab group than in the placebo group (hazard ratio $[\mathrm{HR}]=0.267,95 \%$ CI $0.135-0.528$, $p<0.0001)$. Treatment failure was reported in 10 patients in the rituximab group and 20 in the placebo group. The time-to-treatment failure was significantly longer in the rituximab group than in the placebo group $(\mathrm{HR}=0.268$, $95 \%$ CI $0.122-0.589, p=0.0005)$, and the relapse rate was significantly lower in the rituximab group than in the placebo group (1.542 [29/18.81] vs. 4.171 [46/11.03] per person-years, $\quad \mathrm{HR}=0.370, \quad 95 \% \quad$ CI $0.231-0.591$, $p<0.0001)$. Significantly, fewer patients in the rituximab group experienced frequent relapses or steroid dependence compared with those in the placebo group $(\mathrm{HR}=0.169$, $95 \%$ CI $0.061-0.464, \mathrm{p}=0.0001)$. The daily steroid dose after randomization in the rituximab group was significantly lower than that in the placebo group $(9.12 \pm 5.88$ vs. $20.85 \pm 9.28 \mathrm{mg} / \mathrm{m}^{2} /$ day, $\left.p<0.0001\right)$. The majority of adverse events that were reported were mild and no deaths were reported. Although the rate of serious adverse events was higher in the rituximab group than in the placebo group (42\% [10/24] vs. $25 \%$ [6/24]), but this difference was not significant (Fisher's exact test, $p=0.3587$ ). Mild infusion reactions were reported more frequently in the rituximab group $(79 \%$ [19/24]) than in the placebo group (54\% [13/24]), but this difference was not significant (Fisher's exact test, $p=0.1246$ ). No Grade 3 or 4 infusion reactions were reported in either group. In conclusion, rituximab is safe and effective, at least for 1 year, for the treatment of childhood-onset, complicated FRNS/SDNS [34••].

Based on the results from RCRNS01 and RCRNS02, the use of rituximab for patients with complicated FRNS/ SDNS was approved, for the first time, by the Ministry of Health, Labour and Welfare, Japan on August 29, 2014.

\section{Safety of Rituximab}

More than 500,000 patients worldwide have received rituximab. Serious adverse events have occurred in only a limited number of these patients, while in the majority of patients, rituximab is safe and well tolerated [35]. However, notably, there have been several reports on serious adverse events related to rituximab. Progressive multifocal leukoencephalopathy is a serious adverse event of rituximab (http:// www.fda.gov/safety/medwatch/safetyinformation/safetyrelateddruglabelingchanges/ucm123013.htm). Fetal hepatitis by reactivation of hepatitis $B$ virus is also a serious adverse event induced by rituximab [36]. In recent studies of patients with complicated nephrotic syndrome who had been taking rituximab, a pediatric patient died because of pulmonary fibrosis [37]. Kamei et al. also reported that respiratory events, such as cough, bronchospasm, and dyspnea, are relatively common as adverse effects of rituximab [38]. Sellier-Leclerc et al. reported a patient with fulminant myocarditis due to enterovirus who underwent heart transplant surgery [39]. Additional severe adverse effects reported in childhood nephrotic syndrome include Pneumocystis carinii pneumonia [28, 40] and severe immunemediated ulcerative colitis [41]. These complications might have been underestimated in the literature. Although long-term safety data on anti-CD20 therapy are broadly reassuring, a mortality rate of $3 \%$ has been reported in the 3 years following its initiation in patients with a variety of autoimmune diseases [42], mainly due to infection. The long-term consequences of rituximab infusions in children are not known.

\section{Mechanisms of Rituximab in Nephrotic Syndrome}

The exact pathogenesis of nephrotic syndrome is unknown, but T-cell-mediated immunological abnormalities are thought to play a role [43]. A number of studies have shown that $\mathrm{B}$ cells promote $\mathrm{T}$-cell activation, mediate antibody-independent autoimmune damage, and provide co-stimulatory molecules and cytokines, which can sustain T-cell activation in autoimmune diseases [44-47]. Rituximab induces inhibition of B-cell proliferation and B-cell apoptosis [48]. This action leads to B-cell depletion, and thus suppression of B-cell-T-cell interactions, which might prevent recurrence of nephrotic syndrome. Impaired regulatory $\mathrm{T}$ ( $\mathrm{T}$-reg) cell function in patients with minimal change nephrotic syndrome and induction of remission in nephrotic syndrome by T-reg cells have been previously reported [49-51]. Rituximab may induce an increase in the number and function of T-reg cells [52]. Rituximabmaintained remission in nephrotic syndrome might be due to restoration of T-reg cell function. 
Fornoni et al. recently reported that rituximab directly binds to an acid sphingomyelinase-like phosphodiesterase $3 \mathrm{~b}$ on the cell surface of podocytes, resulting in stability of podocyte structure and function [53]. This may lead to prevention of recurrent focal segmental glomerulosclerosis. Whether a similar mechanism functions in complicated FRNS/SDNS remain to be determined.

\section{Conclusions and Future Perspectives}

Rituximab is a promising option for the treatment of complicated FRNS/SDNS. However, this drug does not cure nephrotic syndrome because all of the patients in the RNRNS01 trial had relapsed by 19 months [34••]. To extend the relapse-free period, further modification of rituximab therapy, including repeated courses and adjunct immunosuppressive therapies, may be necessary. Indeed, a multicenter, double-blind, randomized, placebo-controlled trial to examine the efficacy and safety of mycophenolate mofetil after rituximab therapy for treatment of complicated FRNS/SDNS in children will be started in 2015 in Japan. Moreover, comparison of the efficacy, safety, and cost-effectiveness of various rituximab dosing regimens and B-cell-driven regimens remains to be examined [54]. Further studies are required to examine the long-term effects of rituximab use, particularly in children. A retrospective long-term follow-up study of patients enrolled in RCRNS01 and RCRNS02, focusing on clinical courses, treatments after the clinical trial, growth, and late adverse effects, will be carried out soon in Japan. At present, there is no evidence that rituximab is effective in patients with refractory SRNS. However, Kamei et al. recently reported that additional rituximab combined with conventional methylprednisolone pulse therapy and immunosuppressive agents is a promising option for overcoming refractory SRNS [55]. A multicenter, single-arm trial to examine efficacy and safety of rituximab combined with methylprednisolone pulse therapy and immunosuppressive agents will be started in 2015 in Japan.

Acknowledgments This study was funded by Health and Labour Sciences Research Grants for the Large Scale Clinical Trial Network Project (Japan Medical Association Center for Clinical Trials: CCTB-2001) and for the Clinical Trial on Development of New Drugs and Medical Devices (H25-iryogijutu-ippan-008) from the Ministry of Health, Labour and Welfare, Japan. We thank all of our patients and their families, and physicians who participated in this study.

Open Access This article is distributed under the terms of the Creative Commons Attribution License which permits any use, distribution, and reproduction in any medium, provided the original author(s) and the source are credited.

Disclosure Kazumoto Iijima is an advisor for Zenyaku Kogyo Co., Ltd., received grants from Novartis Pharma K.K., Japan Blood Product Organization, Kyowa Hakko Kirin, Co., Ltd., JCR Pharmaceuticals Co., Ltd., AbbVie Inc, Genzyme Japan K.K., Teijin Pharma Limited, Daiichi Sankyo Company, Limited, Miyarisan Pharmaceutical Co. Ltd., received lecture fees from Kyowa Hakko Kirin, Co., Ltd., Astellas Pharma Inc., Pfizer Japan, Inc., Asahi Kasei Pharma Corp., Kowa Pharmaceutical Co. Ltd., Merck Sharp \& Dohme Corp., ALEXION, Meiji Seika Pharma Co., Ltd., and Novartis Pharma K.K. Mayumi Sako is an advisor for Zenyaku Kogyo Co., Ltd. Kandai Nozu declares no conflict of interest.

Human and Animal Rights and Informed Consent This article does not contain any studies with human or animal subjects performed by any of the authors.

\section{References}

Papers of particular interest, published recently, have been highlighted as:

- Of importance

- Of major importance

1. Eddy AA, Symons JM. Nephrotic syndrome in childhood. Lancet. 2003;362:629-39.

2. Schulman SL, Kaiser BA, Polinsky MS, et al. Predicting the response to cytotoxic therapy for childhood nephrotic syndrome: superiority of response to corticosteroid therapy over histopathologic patterns. J Pediatr. 1988;113:996-1001.

3. The Scientific Committee of the Japanese Society for Pediatric Nephrology. The 2005 Japanese Society for Pediatric Nephrology treatment guideline for idiopathic nephrotic syndrome in children. http://www.jspn.jp/pdf/0505guideline.pdf. Accessed 20 Nov 2013.

4. Hodson EM, Willis NS, Craig JC. Non-corticosteroid treatment for nephrotic syndrome in children. Cochrane Database Syst Rev. 2013;10:CD002290. doi:10.1002/14651858.CD002290.pub4.

5. Hodson EM, Willis NS, Craig JC. Interventions for idiopathic steroid-resistant nephrotic syndrome in children. Cochrane Database Syst Rev. 2010;11:CD003594. doi:10.1002/14651858. CD003594.pub4.

6. Ishikura K, Ikeda M, Hattori S, et al. Effective and safe treatment with cyclosporine in nephrotic children: a prospective, randomized multicenter trial. Kidney Int. 2008;73:1167-73.

7. Ishikura K, Yoshikawa N, Hattori S, Japanese Study Group of Renal Disease in Children, et al. Treatment with microemulsified cyclosporine in children with frequently relapsing nephrotic syndrome. Nephrol Dial Transpl. 2010;25:3956-62.

8. Hamasaki Y, Yoshikawa N, Hattori S, et al. Japanese Study Group of Renal Disease. Cyclosporine and steroid therapy in children with steroid-resistant nephrotic syndrome. Pediatr Nephrol. 2009;24:2177-85.

9. Inoue $\mathrm{Y}$, Iijima $\mathrm{K}$, Nakamura $\mathrm{H}$, Yoshikawa N. Two-year cyclosporin treatment in children with steroid-dependent nephrotic syndrome. Pediatr Nephrol. 1999;13:33-8. 
10. Iijima K, Hamahira K, Tanaka R, et al. Risk factors for cyclosporine-induced tubulointerstitial lesions in children with minimal change nephrotic syndrome. Kidney Int. 2002;61: 1801-5.

11. Edwards JC, Szczepanski L, Szechinski J, et al. Efficacy of B-cell-targeted therapy with rituximab in patients with rheumatoid arthritis. N Engl J Med. 2004;350:2572-81.

12. Stone JH, Merkel PA, Spiera R, et al. Rituximab versus cyclophosphamide for ANCA-associated vasculitis. N Engl J Med. 2010;363(3):221-32.

13. Benz K, Dotsch J, Rascher W, Stachel D. Change of the course of steroid-dependent nephrotic syndrome after rituximab therapy. Pediatr Nephrol. 2004;19:794-7.

14. Nozu K, Iijima K, Fujisawa M, et al. Rituximab treatment for posttransplant lymphoproliferative disorder (PTLD) induces complete remission of recurrent nephrotic syndrome. Pediatr Nephrol. 2005;20:1660-3.

15. Pescovitz MD, Book BK, Sidner RA. Resolution of recurrent focal segmental glomerulosclerosis proteinuria after rituximab treatment. N Engl J Med. 2006;354:1961-3.

16. Yabu JM, Ho B, Scandling JD, Vincenti F. Rituximab failed to improve nephrotic syndrome in renal transplant patients with recurrent focal segmental glomerulosclerosis. Am J Transplant. 2008;8:222-7.

17. Bagga A, Sinha A, Moudgil A. Rituximab in patients with the steroid-resistant nephrotic syndrome. N Engl J Med. 2007;356:2751-2.

18. Kamei K, Okada M, Sato M, et al. Rituximab treatment combined with methylprednisolone pulse therapy and immunosuppressants for childhood steroid-resistant nephrotic syndrome. Pediatr Nephrol. 2014;29:1181-7.

19. Nakayama M, Kamei K, Nozu K, et al. Rituximab for refractory focal segmental glomerulosclerosis. Pediatr Nephrol. 2008;23:481-5.

20. Kaito H, Kamei K, Kikuchi E, et al. Successful treatment of collapsing focal segmental glomerulosclerosis with a combination of rituximab, steroids and ciclosporin. Pediatr Nephrol. 2010;25:957-9.

21. Gulati A, Sinha A, Jordan SC, et al. Efficacy and safety of treatment with rituximab for difficult steroid-resistant and dependent nephrotic syndrome: multicentric report. Clin J Am Soc Nephrol. 2010;5:2207-12.

22. Prytuła A, Iijima K, Kamei K, et al. Rituximab in refractory nephrotic syndrome. Pediatr Nephrol. 2010;25:461-8.

23. Sinha A, Bagga A. Rituximab therapy in nephrotic syndrome: implications for patients' management. Nat Rev Nephrol. 2013;9:154-69.

24. Ito S, Kamei K, Ogura M, et al. Survey of rituximab treatment for childhood-onset refractory nephrotic syndrome. Pediatr Nephrol. 2013;28:257-64.

25. Magnasco A, Ravani P, Edefonti A, et al. Rituximab in children with resistant idiopathic nephrotic syndrome. J Am Soc Nephrol. 2012;23:1117-24.

26. Gilbert RD, Hulse E, Rigden S. Rituximab therapy for steroiddependent minimal change nephrotic syndrome. Pediatr Nephrol. 2006;21:1698-700.

27. Hofstra JM, Deegens JK, Wetzels JF. Rituximab: effective treatment for severe steroid-dependent minimal change nephrotic syndrome? Nephrol Dial Transplant. 2007;22:2100-2.

28. Guigonis V, Dallocchio A, Baudouin V, et al. Rituximab treatment for severe steroid- or cyclosporine-dependent nephrotic syndrome: a multicentric series of 22 cases. Pediatr Nephrol. 2008;23:1269-79.

29. Smith GC. Is there a role for rituximab in the treatment of idiopathic childhood nephrotic syndrome? Pediatr Nephrol. 2007;22:893-8
30. Kamei K, Ito S, Nozu K, Fujinaga S, et al. Single dose of rituximab for refractory steroid-dependent nephrotic syndrome in children. Pediatr Nephrol. 2009;24:1321-8.

31. - Ravani P, Ponticelli A, Siciliano C, et al. Rituximab is a safe and effective long-term treatment for children with steroid and calcineurin inhibitor-dependent idiopathic nephrotic syndrome. Kidney Int. 2013;84:1025-33. This case series is a relatively large, and showing a promising result of rituximab for the treatment of children with steroid and calcineurin inhibitordependent idiopathic nephrotic syndrome.

32. - Ruggenenti P, Ruggiero B, Cravedi P, et al. Rituximab in Nephrotic Syndrome of Steroid-Dependent or Frequently Relapsing Minimal Change Disease Or Focal Segmental Glomerulosclerosis (NEMO) Study Group. Rituximab in steroiddependent or frequently relapsing idiopathic nephrotic syndrome. J Am Soc Nephrol. 2014;25:850-63. This case series also demonstrated a promising result of rituximab for the treatment of complicated FRNS/SDNS.

33. - Ravani P, Magnasco A, Edefonti A, et al. Short-term effects of rituximab in children with steroid- and calcineurin-dependent nephrotic syndrome: a randomized controlled trial. Clin J Am Soc Nephrol. 2011;6:1308-15. This is the first randomized controlled trial to examine the efficacy of rituximab for patients with complicated FRNS/SDNS although it has several limitations such as small sample size, non-inferiority design and open-label trial.

34. •• Iijima K, Sako M, Nozu K, et al. Rituximab for childhoodonset, complicated, frequently relapsing nephrotic syndrome or steroid-dependent nephrotic syndrome: a multicentre, doubleblind, randomised, placebo-controlled trial. Lancet. 2014;384(9950):1273-81. doi:10.1016/S0140-6736(14)60541-9. This is the first multicenter, double-blind, randomized, placebocontrolled trial to examine the efficacy and safety of rituximab for the treatment of complicated frequently relapsing nephrotic syndrome or steroid-dependent nephrotic syndrome in children.

35. Kimby E. Tolerability and safety of rituximab (MabThera). Cancer Treat Rev. 2009;31:456-73.

36. Tsutsumi Y, Kanamori $\mathrm{H}$, Mori A, et al. Reactivation of hepatitis B virus with rituximab. Expert Opin Drug Saf. 2005;4:599-608.

37. Chaumais MC, Garnier A, Chalard F, et al. Fatal pulmonary fibrosis after rituximab administration. Pediatr Nephrol. 2009;24:1753-5.

38. Kamei K, Ito S, Iijima K. Severe respiratory adverse events associated with rituximab infusion. Pediatr Nephrol. 2010;25:1193.

39. Sellier-Leclerc AL, Belli E, Guérin V, et al. Fulminant viral myocarditis after rituximab therapy in pediatric nephrotic syndrome. Pediatr Nephrol. 2013;28:1875-9.

40. Sato M, Ito S, Ogura M, Kamei K, et al. Atypical Pneumocystis jiroveci pneumonia with multiple nodular granulomas after rituximab for refractory nephrotic syndrome. Pediatr Nephrol. 2013;28:145-9.

41. Ardelean DS, Gonska T, Wires S, et al. Severe ulcerative colitis after rituximab therapy. Pediatrics. 2010;126:e243-6.

42. Tony HP, Burmester G, Schulze-Koops H, et al. Safety and clinical outcomes of rituximab therapy in patients with different autoimmune diseases: experience from a national registry (GRAID). Arthritis Res Ther. 2011;13:R75.

43. Shalhoub RJ. Pathogenesis of lipoid nephrosis: a disorder of T-cell function. Lancet. 1974;2:556-60.

44. Liu K, Mohan C. Altered B-cell signaling in lupus. Autoimmun Rev. 2009;8:214-8.

45. Chan OT, Hannum LG, Haberman AM, Madaio MP, Shlomchik MJ. A novel mouse with B cells but lacking serum antibody 
reveals an antibody-independent role for B cells in murine lupus. J Exp Med. 1999;189:1639-48.

46. Sfikakis PP, Boletis JN, Lionaki S, et al. Remission of proliferative lupus nephritis following B cell depletion therapy is preceded by down-regulation of the $\mathrm{T}$ cell costimulatory molecule CD40 ligand: an open-label trial. Arthritis Rheum. 2005;52:501-13.

47. Bugatti S, Codullo V, Caporali R, Montecucco C. B cells in rheumatoid arthritis. Autoimmun Rev. 2007;7:137-42.

48. Maloney DG. Mechanism of action of rituximab. Anticancer Drugs. 2001;12(Suppl 2):S1-4.

49. Araya C, Diaz L, Wasserfall C, et al. T regulatory cell function in idiopathic minimal lesion nephrotic syndrome. Pediatr Nephrol. 2009;24:1691-8.

50. Hashimura Y, Nozu K, Kanegane H, et al. Minimal change nephrotic syndrome associated with immune dysregulation, polyendocrinopathy, enteropathy, X-linked syndrome. Pediatr Nephrol. 2009;24:1181-6.
51. Le Berre L, Bruneau S, Naulet J, et al. Induction of T regulatory cells attenuates idiopathic nephrotic syndrome. J Am Soc Nephrol. 2009;20:57-67.

52. Stasi R, Cooper N, Del Poeta G, et al. Analysis of regulatory T-cell changes in patients with idiopathic thrombocytopenic purpura receiving B cell-depleting therapy with rituximab. Blood. 2008;112:1147-50.

53. Fornoni A, Sageshima J, Wei C, et al. Rituximab targets podocytes in recurrent focal segmental glomerulosclerosis. Sci Transl Med. 2011;3:85ra46.

54. Cravedi P, Ruggenenti P, Sghirlanzoni MC, Remuzzi G. Titrating rituximab to circulating $\mathrm{B}$ cells to optimize lymphocytolytic therapy in idiopathic membranous nephropathy. Clin J Am Soc Nephrol. 2007;2:932-7.

55. Kamei K, Okada M, Sato M, et al. Rituximab treatment combined with methylprednisolone pulse therapy and immunosuppressants for childhood steroid-resistant nephrotic syndrome. Pediatr Nephrol. 2014;29:1291-2. 